\title{
A PRÁtica PEDAGógica dos MESTRES de CARATÊ DA GRANDE VITÓRIA (ES)
}

\author{
Yúri Márcio Lopes \\ Discente do Programa de Pós-Graduação em Educação Física (mestrado) do CEFD/UFES. \\ Otávio Guimarães Tavares \\ Professor do Programa de Pós-Graduação em Educação Física (mestrado) do CEFD/UFES.
}

\begin{abstract}
Resumo
Este estudo propõe investigar o tipo de prática de ensino dos "mestres" de caratê nas academias da Grande Vitória (ES). A metodologia adotada consiste em coleta de dados por meio da observação e da aplicação de entrevistas estruturadas. Os dados coletados evidenciam que os conteúdos são tratados de maneira dogmática; a metodologia é baseada na explicação oral e demonstrações do professor; a relação professor-aluno favorece as decisões unilaterais do professor, e, na avaliação, verifica-se a exatidão das técnicas ensinadas. Em síntese, pode-se concluir que a presença dos valores da tradição e do esporte nas aulas de caratê é fator impeditivo para adoção de práticas pedagógicas mais críticas e significativas.

Palavras-chave: caratê - pedagogia do esporte - prática pedagógica.
\end{abstract}

\section{Introdução}

$\mathrm{O}$ caratê é uma arte marcial milenar que ao longo de sua história tem sofrido transformações de seus significados e sentidos sócio-culturais. Em sua dimensão contemporânea, é reconhecido popularmente como um esporte de luta. Dadas as condições de seu contexto histórico-social, verifica-se que o caratê assumiu valores da tradição japonesa transmitidos especialmente por meio da narrativa oral (VIANNA, 1995), o que tem determinado sua identidade e, particularmente para o que interessa a este estudo, suas formas e estratégias de aprendizagem.

A motivação para este estudo foi a construção de uma reflexão sobre o ensino do caratê como uma prática pedagógica. Assim, o objetivo deste artigo é analisar a concepção de ensino e a prática pedagógica dos professores de caratê da Grande Vitória - GV (ES). Neste sentido, cabe inicialmente discutir como é possível pensar o ensino do caratê como uma prática pedagógica.

O debate acadêmico aponta para o delineamento de concepções de educação no sentido lato e no sentido estrito. Isto se articula com a necessidade de determinação das interfaces que se estabelecem entre a especificidade do papel social escolar e as práticas sociais nãoescolares. Ao fazer uma revisão das diversas concepções de educação, Libâneo (2001) elabora uma síntese da concepção históricosocial abordando dois conceitos de educação:

\footnotetext{
Em sentido amplo, a educação compreende o conjunto dos processos formativos que ocorrem no meio social, sejam eles intencionais ou não-intencionais, sistematizados ou não, institucionalizados ou não... Em sentido estrito, a educação diz respeito a formas intencionais de promoção do desenvolvimento individual e de inserção social dos indivíduos, envolvendo especialmente a educação escolar e extra-escolar (LIBÂNEO, 2001, p. 74).
} 
Nessa passagem, ao discutir sobre as modalidades da educação intencional, Libâneo faz distinção de dois tipos: a não-formal e a formal. Para ele, o termo "educação formal” refere-se àquela educação estruturada, organizada, planejada intencionalmente e sistemática. Por outro lado, a educação nãoformal seria aquele conjunto de atividades com caráter de intencionalidade, implicando certamente relações pedagógicas, porém com baixo grau de estruturação e sistematização. Nestes termos, a educação escolar se configura na modalidade de educação formal. Isto não significa dizer que não aconteça educação formal em outros tempos/espaços sociais, ou seu oposto, ou seja, práticas da educação nãoformal na própria escola (atividades extra-escolares). $\mathrm{O}$ autor esclarece que:

onde haja ensino (escolar ou não) há educação formal. Nesse caso, são atividades educativas formais também a educação de adultos, a educação sindical, a educação profissional, desde que nelas estejam presentes a intencionalidade, a sistematicidade e condições previamente preparadas, atributos que caracterizam um trabalho pedagógico-didático, ainda que realizadas fora do marco escolar propriamente dito (LIBÂNEO, 2001, p. 81).

Em abordagem semelhante, Souza Júnior (2001) faz uma análise sistemática do termo "prática pedagógica". Ele procura compreender o seu surgimento na educação física, os delineamentos conceituais e contextuais, seus argumentos de sustentação na educação física e, por fim, apresenta a sua hipótese acerca da compreensão de prática pedagógica da educação física nas várias instâncias organizacionais em que está presente. Souza Júnior (2001, p. 9) afirma que "a educação física é uma prática pedagógica mesmo em diferentes tempos e espaços sociais, inclusive para além da escola".

Inspirando-nos nestes autores, poderíamos admitir que na prática de ensino dos professores de caratê há certo grau de estruturação pedagógica. Ou seja, o ensino do caratê configura-se como uma prática pedagógica. Em face dessas discussões parece ser relevante investigar que elementos caracterizam a prática de ensino dos professores de caratê.

\section{Metodologia}

A coleta de dados foi realizada por meio da técnica de observação das aulas, durante uma semana seguida, e da aplicação de uma entrevista estruturada com cada um dos respectivos professores observados.

A partir do conjunto dos professores de caratê filiados à Federação Espírito-Santense de Karatê (FEK) foram selecionados três professores, segundo os seguintes critérios: [1] maior tempo de prática de ensino; [2] maior reconhecimento pelos pares de sua atuação no caratê na GV; e [3] maior número de alunos. É importante frisar que nenhum dos professores tem formação em educação física. ${ }^{1}$

Para a sistematização dos dados da observação foi elaborada uma lista de checagem. Nesta lista eram descritos previamente os critérios de análise, acompanhando as características das tendências pedagógicas liberais e progressistas, tal como classificadas por $\mathrm{Li}^{-}$ bâneo (1993). Foi considerado também um espaço para a descrição das ações dos professores. Considerando que o contexto da prática pedagógica dos professores de caratê está circunscrito fora do ambiente escolar, utilizamos como categorias de análise os elementos "conteúdos", "metodologia", "relação professor-aluno", "pressupostos de aprendizagem" e "avaliação".

Considerando os respectivos elementos que compõem a prática pedagógica, as argumentações e discursos dos professores foram coletados por meio de uma entrevista com perguntas de tipo aberta. Esta técnica foi utilizada com o intuito de complementar e/ou contrastar com os dados oriundos da obser-

\footnotetext{
1 De acordo com as informações obtidas nesta Fede-
} ração existe oito academias filiadas. 
vação. As entrevistas foram realizadas em um ambiente neutro, para minimizar possíveis interferências de outras pessoas e restrições temporais. Para análise dos dados das entrevistas, utilizamos a técnica de análise de discurso.

\section{Apresentação e análise dos resultados}

Uma vez que as diferentes técnicas de coleta de dados utilizadas estão relacionadas a uma mesma questão de investigação, a discussão dos resultados baseou-se na análise combinada de observações e entrevistas de modo a facilitar a construção de sínteses.

\section{Conteúdos de ensino}

Durante a observação pôde ser verificado que, na prática pedagógica dos professores de caratê, predominou a preocupação com transmissão de conhecimentos. Como registramos em nosso diário de campo: "Ao ensinar um fundamento técnico (soco guiaku-zuki), o professor explicava e demonstrava como saltitar e aproximar do adversário com maior rapidez. No ensino da luta, o professor dava ênfase ao aperfeiçoamento no controle do contato físico, segundo as regras de competição" (aula do mestre A).

Os professores observados explicavam os conteúdos (valores pedagógicos do caratê, fundamentos técnicos - ataque, defesa, contra-ataque e deslocamentos, os katas e o kumitê) a partir de experiências adquiridas, variando entre os sentidos/significados do caratê para a autodefesa e para o esporte.

Verificamos que os valores da tradição e do esporte permeiam os conteúdos do ensino do caratê. Ambos os elementos, na prática de ensino dos professores, permitem um ensino que se fundamenta em "verdades" baseadas no discurso da tradição e no imobilismo das regras de competição. Nestes termos, os dados puderam evidenciar que os conteúdos de ensino se aproximam do ensino tradicional, tal como classificado por Libâneo (1993, p.
24): "São os conhecimentos e valores acumulados pelas gerações adultas e repassados ao aluno como verdades".

Quanto ao aspecto das habilidades a serem apreendidas pelos alunos, percebemos, na observação das aulas, um ensino mecânico. A ênfase na prática de ensino, principalmente para as crianças e adolescentes, pode limitar o potencial criativo dos alunos para novas possibilidades de movimento. As aulas de caratê poderiam ser enriquecidas com o sentido lúdico, com o destaque na ampliação das possibilidades de movimentos para aumentar o repertório de forma criativa, sem que isto necessariamente implicasse na "invenção de um estilo novo".

\section{Métodos de ensino}

Observamos que havia nas aulas certo grau de estruturação. Regularmente iniciava-se com os rituais de saudação ao mestre Gishin Funakoshi cuja figura estava presente por meio de um quadro afixado na parede e ao professor. Em seguida eram realizados os exercícios de aquecimento, o desenvolvimento dos conteúdos da aula e finalizava com os mesmos ritos de saudação. ${ }^{2}$

Do mesmo modo, constatamos um grau de sistematização das aulas. O aprendizado e o aperfeiçoamento das técnicas eram feitos, primeiramente, pela repetição parcial dos movimentos ou conjugando-os (kihon), considerando o nível de aprendizagem dos alunos. Depois, era realizado o aprendizado/ treino da luta e/ou dos katas com base nas atividades feitas anteriormente, dependendo da faixa de graduação dos alunos, preparando-os para futuras competições. Freqüentemente era adotado o uso do rodízio entre os alunos no momento da luta a fim de favorecer a troca de experiências entre eles. ${ }^{3}$

2 Segundo a tradição oral, o mestre Gishin Funakoshi foi o pai do caratê moderno.

3 De acordo com Paula (1996), os katas de competição são aqueles listados pelos quatro estilos mais impor- 
Constatamos também, na prática de ensino dos katas, uma preocupação dos professores para além da repetição exaustiva dos movimentos padronizados. Para compreendê-los seria necessário saber aplicar cada movimento, já que os mesmos representam uma simulação da luta. Apesar de os alunos até ensaiarem novos sentidos aos movimentos, as "verdadeiras" e "inquestionáveis" interpretações deles estavam centradas no professor.

As razões mobilizadas pelos professores para considerar corretos determinados $\mathrm{pa}^{-}$ drões de movimentos evidenciam a presença e a força da tradição oral do caratê e o caráter imobilista desta prática pedagógica. Segundo eles: "Isso é assim porque sempre foi assim. Isso vem da tradição. O caratê é uma arte milenar" (entrevistado B).

Considerando que os atores sociais fazem uso de esquemas racionais para justificar as ações, o uso de tais argumentos pode ser classificado como a manifestação de uma racionalidade de tipo tradicional (BOUDON, 1996). É evidente que os professores de caratê mobilizam os argumentos baseados na tradição para explicar as situações que emergem no cotidiano das práticas pedagógicas de forma a dar um caráter racional para suas ações. Porém, é preciso considerar que a base desse tipo de discurso situa-se em um contexto mais amplo, construído ao longo da história do caratê e que auxilia a constituir a sua própria identidade.

De modo predominante, os professores mobilizam o conhecimento de suas próprias experiências no caratê, com especial atenção às competições, para ensinar os conteúdos pela explicação oral e pela demonstração.

Observamos que as técnicas são ensinadas como receitas. Os professores explicam a postura "correta" para cada movimento, assim

tantes reconhecidos pela Federação Mundial de Karatê (Goju ryu, Shito Ryu, Shotokan e Wado Ryu) que procura assegurar os principais katas de cada estilo. como os procedimentos a serem repetidos pelos alunos, de forma idêntica e exaustiva. Assim, de acordo com a classificação de Libâneo (1993), pode ser dito que as características do ensino do caratê se aproximam da tendência tradicional. Como afirma o autor,

os métodos baseiam-se na exposição verbal da matéria e/ou demonstração. Tanto a exposição quanto à análise são feitas pelo professor [...] A ênfase nos exercícios, na repetição de conceitos ou fórmulas na memorização visa disciplinar a mente e formar hábitos (LIBÂNEO, 1993, p. 24).

\section{Relação professor-aluno}

Os professores deixam transparecer, nas suas ações, o entendimento de que o relacionamento com os alunos durante as aulas deveria ser hierarquizado. Ao entrar no dojô, o aluno sempre deve estar "abaixo" do professor.

O professor explica o que os alunos devem fazer e eles apenas executam em conjunto. $\mathrm{O}$ controle da quantidade e qualidade dos movimentos, assim como o momento de descanso, é definido pelo professor. Aos alunos cabe somente a repetição dos exercícios. Nesse contexto, durante as aulas, a comunicação entre os alunos ocorre somente nos intervalos de descanso.

O caráter da relação vertical entre professor-aluno é reforçado nas falas dos entrevistados. Por exemplo, ao levantar a questão "o que significa ser professor para você?”, um dos entrevistados respondeu: "Significa ser responsável em proporcionar às pessoas ensinamentos técnicos e filosóficos de cultura oriental de apreciação mundial" (entrevistado $\mathrm{C}$ ).

Nesse sentido, o tipo de relação professoraluno estava sustentado na hierarquia e na disciplina. Acredita-se que os valores da tradição são reforçadores para que a relação professoraluno seja verticalizada. A atenção é enfatizada pela seriedade e respeito ao professor que transmite os conhecimentos práticos. 
Ao analisar os dados anteriores, podemos verificar que a relação professor-aluno na prática pedagógica dos professores de caratê apresenta semelhanças com o ensino tradicional. Para Libâneo (1993, p. 24), o relacionamento entre professor e aluno:

Predomina a autoridade do professor que exige atitude receptiva dos alunos e impede qualquer comunicação entre eles no decorrer da aula. O professor transmite o conteúdo na forma de verdade a ser absorvida; em conseqüência, a disciplina imposta é o meio mais eficaz para assegurar a atenção e o silêncio.

\section{Pressupostos de aprendizagem}

Os alunos apreendem os movimentos pela imitação do professor ou de alunos mais graduados. Os professores condicionam os alunos, independentemente da idade, a repetirem as técnicas com os estímulos, variando entre as contagens em japonês e as entonações da voz. A repetição dos movimentos é reforçada de acordo com as respostas pretendidas pelo professor, com as correções da postura e exatidão das técnicas, por meios de fundamentos orientados à luz da narrativa oral ou das normas do esporte.

Confrontando os dados observados com o que pensa Libâneo (1993), verificamos uma proximidade maior com algumas características da tendência liberal tradicional. Segundo as características dessa tendência, o autor afirma que:

a capacidade de assimilação da criança é idêntica à do adulto, apenas menos desenvolvida. Os programas, então, devem ser dados numa progressão lógica, estabelecida pelo adulto, sem levar em conta as características próprias de cada idade. A aprendizagem, assim, é receptiva e mecânica (LIBÂNEO, 1993, p. 24).

Os fatos observados, de certo modo, são complementados com o discurso dos professores nas entrevistas. Os professores acreditam que, para aprender a lutar caratê, os alunos devem passar por processo de ensi- no-aprendizagem, partindo do aprendizado e treino dos fundamentos técnicos elementares aos movimentos mais complexos. Quando foi solicitado a explicar, com as próprias palavras, como os alunos aprendem, um dos entrevistados respondeu: "A aplicação dos conhecimentos deve ser um exercício constante na luta ou nos katas. O aprimoramento de cada golpe ou técnica deve estar sempre presente numa seqüência de aprendizado" (entrevistado C).

\section{Avaliação}

A observação é o instrumento de avaliação mais utilizado pelos professores, mas não o único. Os alunos são avaliados no cotidiano de forma qualitativa com base no desempenho técnico, verificando a correspondência entre as demonstrações feitas e a exatidão na execução. $\mathrm{O}$ olhar dos professores está centrado na observância do grau de proximidade das formas de movimentos ensinadas e aquelas exibidas pelos alunos. Isto ficou evidente na entrevista com a questão: "Como você avalia a aprendizagem dos alunos? Quais são os critérios?" Um dos professores respondeu: "De modo observacional durante a prática de cada um nas aulas. Bom, os critérios são a execução correta dos movimentos e a aplicação correta das técnicas" (entrevistado B).

Notamos que os professores fazem constantes correções quanto à direção do olhar, trajetória dos golpes, distância adequada em relação ao adversário na luta, quanto à postura corporal para cada técnica de ataque, defesa e deslocamento. Nas intervenções, o professor identifica as ações dos alunos que não correspondem às suas expectativas. Para cada faixa de graduação é exigido o domínio de um conjunto de habilidades técnicas no kihon, kata e kumitê. Porém, os katas foram os únicos cujos critérios apresentaram convergência no discurso dos professores. ${ }^{4}$

4 No caratê, as faixas de graduação marcam os níveis de aprendizagem. As cores das faixas variam de acor- 
Foi constatado nas entrevistas que as competições servem, também, como instrumento de avaliação para verificar quanto o aluno assimilou dos conhecimentos técnicos. É atribuído às competições um momento relevante a ser considerado nas avaliações por colocar o aluno diante de situações adversas para observar a aprendizagem do autocontrole, da disciplina e do amadurecimento. Contudo, não foram registradas, neste estudo, considerações dos professores investigados sobre os limites educativos do tipo de modelo competitivo a que os alunos estão sujeitos. Deste modo, concordamos com Freire (1997) quando propõe a necessidade do trato pedagógico para as competições no sentido da valorização de todos os competidores, em detrimento do fomento da busca pela vitória a qualquer custo.

Considerando que a avaliação para os professores é verificação de quanto o aluno pôde reter dos conteúdos ensinados, seja na forma de execução estereotipada, seja pelo desempenho nas competições, verificamos que há uma aproximação com as características da tendência pedagógica liberal tradicional.

É preciso, porém, fazer uma ressalva em relação às limitações da análise sobre a avaliação dos professores de caratê à luz do quadro das tendências pedagógicas de Libâneo (1993), usado como referencial teórico, uma vez que seu caráter formal e burocrático é bem mais claro, definido e institucionalizado no sistema escolar do que nas escolinhas de caratê analisadas.

\section{Conclusão}

Podemos concluir que os conteúdos são transmitidos como "verdades" a serem assimiladas pelos alunos com a prevalência da reprodução passiva e repetição mecânica. A estrutura das aulas guarda semelhanças com uma

do com os estilos de caratê. É majoritário que a primeira e a última faixa de graduação seja a branca e a preta, respectivamente. sessão de treinamento, com o predomínio dos métodos da explicação oral e a demonstração centrada no professor. A sistemática de ensino parte do método parcial (kihon) para o global das técnicas do caratê (kata e kumitê) e as estratégias de ensino por comando. Foi evidente a relação hierarquizada entre professor e aluno, cabendo ao professor o controle da aula e aos alunos a imitação passiva. Para a avaliação do aprendizado, os professores utilizam a observação e os exames de graduação para verificar a exatidão da correspondência dos conteúdos ensinados.

Face ao exposto, as práticas pedagógicas dos professores de caratê, aqui estudadas, caracterizam-se, predominantemente, por uma forma de tipo liberal tradicional. Os professores analisados estão orientados por uma concepção de ensino estático e acrítico. Assim, sua concepção de ensino parece contrariar o movimento dinâmico da produção do conhecimento e contemplar uma concepção essencialista do homem (SAVIANI, 1985), reforçada pelo modelo de racionalidade predominantemente tradicional (BOUDON, 1996) e pela influência do sistema esportivo.

Apesar da proximidade com as características da pedagogia tradicional, é relevante considerar as implicações dos valores da tradição e do esporte na prática de ensino. Podemos observar que esses elementos estiveram presentes na narrativa oral dos professores. Isto se deve ao fato que, não tendo formação pedagógica em educação física, o grande referencial para estruturar suas aulas é a própria experiência de formação na luta.

Se a prática do caratê for considerada entre as dimensões da Cultura de Movimento (KUNZ, 2005), esta poderá ser tratada pedagogicamente no sentido de uma formação humanizadora. Para a construção de uma "pedagogia do caratê", diferente daquela evidenciada na prática pedagógica dos professores de caratê estudada, seriam necessários articular novos valores orientadores para o ensino. 
A análise empreendida deixa em aberto a seguinte questão: considerando os valores da tradição e a influência do esporte na "pedagogia do caratê", em que medida é possível articular outros valores para a intervenção pedagógica do caratê para a formação de sujeitos mais autônomos e críticos? Parece que este é o desafio a ser enfrentado.

Pedagogical practice among karate instructors in the Greater Vitória (ES) area

\begin{abstract}
This research work aims at investigating teaching practices among karate instructors in the gyms of the greater Vitoria area (ES). The adopted methodology consists of data collection through observation, and structured interviewing. The collected data show that contents are treated in a dogmatic manner; methodology is based on oral explanations and teacher demonstrations; the teacher-student relationship favors one-sided decisions made by the teacher; examinations verify accuracy of techniques taught. In a summary, one can conclude that the presence of tradition and sports values in karate lessons is a blocking factor to the adoption of more critical and meaningful pedagogical practices.
\end{abstract}

Keywords: karate - sport pedagogy - pedagogical practices.

\section{La práctica pedagógica de los experts del karate de Grande Vitória (ES)}

\section{Resumen}

Este estudio propone investigar el tipo de práctica de enseñanza de los "expert" en karate en las academias de Grande Vitória (ES). La metodología adoptada consistió en la recolección de datos por medio de la observación y de la aplicación de entrevistas estructuradas. Los datos reunidos evidencian que los contenidos son tratados de una manera dogmática; la metodología es basada en la explicación oral y las demostraciones del profesor; la relación profesor-alumno favorece las decisiones unilaterales del profesor, y, en la evaluación, se verifica la exactitud de las técnicas enseñadas. En síntesis, se puede concluir que la presencia de los valores de la tradición y del deporte en las clases del karate es un factor que impide la adopción de prácticas pedagógicas más críticas y significativas.

Palabras-clave: karate - pedagogía del deporte práctica pedagógica.

\section{Referências}

BOUDON, R. Tratado de Sociologia. Rio de Janeiro: Zahar, 1996.

FREIRE, J. B. Educação de corpo inteiro: teoria e prática da educação física. São Paulo: Scipione, 1997.

KUNZ, E. Cultura de movimento. In: GONZÁLEZ, F.; FENSTERSEIFER, P. Dicionário crítico de educação física. Ijuí: Unijuí, 2005. p. 111-113.

LIBÂNEO, J. C. Democratização da escola pública: a pedagogia crítico-social dos conteúdos. 11. ed. São Paulo: Edições Loiola, 1993.

Pedagogia e pedagogos para quê? 4. ed.

São Paulo: Cortez, 2001.

PAULA, G. G. Karatê esporte: tática \& estratégia. São Paulo: IBRASA, 1996.

SAVIANI, D. Tendências e correntes da educação brasileira. In: SAVIANI, D. et. al. Filosofia da educação brasileira. 2. ed. Rio de Janeiro: Civilização Brasileira, 1985. p. 19-47.

SOUZA JÚNIOR, M. A prática pedagógica da educação física nos tempos e espaços sociais. In: CONGRESSO BRASILEIRO DE CIÊNCIAS DO ESPORTE, 12., 2001, Caxambu. Anais... Caxambu, 2001.

VIANNA, J. A. Valores tradicionais do karatê: uma aproximação histórica e interpretativa. 1995. 117 f. Dissertação (Mestrado em Educação Física) - Centro de Educação Física e Desportos, Universidade de Gama Filho, Rio de Janeiro, 1995.

Recebido: 28 de setembro de 2007

Aprovado: 23 de outubro de 2007

Endereço para correspondência

yurims1@ebrnet.com.br

tavaresotavio@yahoo.com.br 